\title{
Multisector Collaboration: An Action Research Approach
}

\author{
Sarena Saunders, Victoria University of Wellington, New Zealand
}

\begin{abstract}
This article provides an overview of the action-oriented research literature - making a case for a methodological approach that endeavors to lessen the gap between theory and practice in the context of a multisector collaborative effort. A brief description of the first author's involvement in an action-oriented research project illustrates this point from the perspectives of the board of directors of a (then) newly-created joint venture with thirteen partner organizations representing the academic, pharmaceutical industry and government sectors. The contribution lies in demonstrating the utility of an action research approach when the overall objective of the research is to gain insights into the phenomenon of interest while simultaneously having these insights available to directly inform management practice.
\end{abstract}

Keywords: literature review, action research, multisector collaboration, case study

\section{BACKGROUND AND INTRODUCTION TO THE CASE}

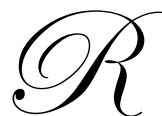

esearchers increasingly utilize the term 'action research' to describe and justify their endeavors (Cassell and Johnson, 2006). This paper provides a context for an action research approach drawing on an historical case study of a multi-party, multisector joint venture in which the progress of the research and the study findings were communicated to senior venture management in an effort to influence practice and optimize the collaborative efforts of the participants. The first section of this article briefly introduces this case before reviewing the key tenets of action inquiry methodological approaches. A case is then made for decreasing the gap between theory and practice by reviewing the methodological and ideological foundations for an action inquiry approach to organizational analysis, before explaining why the action-based approach was selected and how it was utilized in the study of this multi-party, multisector joint venture. An action-oriented research approach makes certain assumptions regarding the research process. Table 1 illustrates some of these assumptions.

During 1995, fourteen government, academic, and industry organizations collaborated to form the Institute of Pharmaco-Economics (IPE). The Institute was comprised of founding partners including seven multi-national pharmaceutical companies, two universities, and five government departments/agencies at both the provincial and federal level. Two years into its operations, the lead author of this paper began to study IPE as an example of a multi-sector collaborative venture and an action-based research strategy was selected. The major objective of this paper is to explicate through illustration, why this action-based strategy was appropriate for the study of multisector collaboration when at the time, a major objective had been to conduct research where the research process itself along with the research findings would have the opportunity to inform the ongoing management of such collaborative efforts in real time - not through the more typical avenue of conducting the research, writing it up in a journal article with managerial implications, publishing it in an appropriate journal and then hoping that the implications of the article would find their way into managerial practice. The case will be revisited later in the paper but it is first appropriate to introduce an underlying motive behind any piece of action research. An opening premise of this article is that there is a problematic gap in much traditional organizational inquiry because of the separation of the researcher from the researched and in addition, Susman and Evered (1978) argue that as research methodologies becomes more sophisticated, there is an ever-widening gap between theory and utility in the service of organizational problem solving. By adhering to a narrow view of what constitutes valid, scientific inquiry, and recognizing that this limits the scope and impact of organizational research, researchers can promote and put into 
practice newer, more holistic approaches to examining organizational phenomena. Action research or action inquiry constitutes one such group of related methodological approaches.

Table 1: Assumptions of Action-Oriented Research

\begin{tabular}{|c|c|c|}
\hline & Action Research & References \\
\hline Ontology & $\begin{array}{l}\text { Reality is objectively given but } \\
\text { subjectively represented }\end{array}$ & $\begin{array}{l}\text { Hussey and Hussey (1997); } \\
\text { Guba and Lincoln (1994) }\end{array}$ \\
\hline \multirow[t]{2}{*}{ Epistemology } & $\begin{array}{l}\text { Manager/practitioner and } \\
\text { academic can both contribute } \\
\text { specific and general knowledge }\end{array}$ & Susman and Evered (1978) \\
\hline & $\begin{array}{l}\text { Co-production of knowledge, } \\
\text { both parties are experts }\end{array}$ & Rowan (1981); Slominowski (1994) \\
\hline Aims & $\begin{array}{l}\text { Development of guides for } \\
\text { taking action }\end{array}$ & $\begin{array}{l}\text { Heron (1981); Susman and } \\
\text { Evered (1978) }\end{array}$ \\
\hline $\begin{array}{l}\text { Timing of } \\
\text { outcomes }\end{array}$ & $\begin{array}{l}\text { Immediacy of outcomes/ } \\
\text { findings }\end{array}$ & Susman and Evered (1978) \\
\hline $\begin{array}{l}\text { Time } \\
\text { Perspective }\end{array}$ & Future orientation & Emery (1967) \\
\hline \multirow[t]{2}{*}{ Methodology } & $\begin{array}{l}\text { Incorporates training to } \\
\text { improve performance of } \\
\text { managers. }\end{array}$ & Lewin (1946); Heron (1981) \\
\hline & $\begin{array}{l}\text { Cyclical, multi-stage } \\
\text { process allows adaptation }\end{array}$ & Chein (1948); Heron (1981) \\
\hline Validation & $\begin{array}{l}\text { Occurrence of intended } \\
\text { outcomes }\end{array}$ & Susman and Evered (1978) \\
\hline
\end{tabular}

Adapted from Daniel and Wilson (2004)

\section{DEFINING ACTION-ORIENTED RESEARCH}

Arriving at a consensus definition is one of the major obstacles to the acceptance, and utilization of any newly-introduced concept. Action inquiry is no exception, since researchers with different objectives tend to emphasize different aspects of these research strategies. Although its origins are somewhat in dispute, most action researchers tend to credit social psychologist Kurt Lewin (1946) with coining the term action research, as a means of generating knowledge about a social system while at the same time, attempting to change it. His conception of action research as a cyclical inquiry process consists of diagnosing a problem situation, planning action steps, and implementing and evaluating outcomes (Elden and Chisholm, 1993).

Focusing on the goals of action research, Robinson (1993, p. 265) cites a definition developed by Kemmis: "Action research is a form of self-reflective inquiry undertaken by participants in social (including educational) situations in order to improve the rationality and social justice of: (a) their own social or educational practices, (b) their understanding of these practices, and (c) the situation in which the practices are carried out".

Robinson concludes that in examining the various definitions of action research, three main goals can be derived. Hence, action research involves:

- The improvement of practice,

- The improvement of practitioners' ability to improve their practice, including relevant practice contexts,

- $\quad$ The generation of knowledge about practice and the improvement process. 
It is the cyclical nature of diagnosing, action planning, action taking, evaluating, and specifying learning that are the key facets of action research. This key facet of taking action is one that traditional quantitative organizational research does not ordinarily include. Ignoring local theories-in-use and multiple perspectives of organizational groups results in missed opportunities for:

- Uncovering implicit action-related assumptions and beliefs and stakeholder differences therein,

- Distinguishing between contextual factors that are and are not integral to the conceptualization and implementation of action, in addition to identifying the influential causal contextual factors, and

- Using the contextually grounded framework of local theory as one interpretive frame for inquiry findings (Greene, 1993).

Israel, Schurman, and Hugentobler (1992) further support this in their assessment of the six necessary conditions for conducting action research. They state that action research is participatory, cooperative/collaborative, a co-learning experience, involves system development, an empowering process, and it achieves a balance between research and action. Therefore, one of the key components of any sort of action research is the collaborative nature of investigation since individuals, individual theoretical frameworks, and individual disciplinary or sectoral approaches can effectively deal with complicated and serious issues (Schensul and Stull, 1987).

Reason (2006) focuses on the issue of quality in action research practice and concludes that to optimize the quality of the research, researchers must have an awareness and transparency about the choices available to them. These choices include consideration of issues such as (a) the extent to which the action research involves pursuing worthwhile purposes, (b) the extent to which building democratic, participative, pluralist communities of inquiry is central to the research, (c) acknowledging that there are many ways of knowing and that knowledge is multi-faceted, and finally (d) that action research is an evolutionary and developmental process not a programmatic one.

\section{CONDUCTING ACTION-ORIENTED RESEARCH}

Action inquiry operates not only on a number of levels, and in a number of different contexts but also across a number of different disciplines including management (Mårtensson and Lee, 2004), marketing (Perry and Gummesson, 2004), operations research (Prybutok and Ramasesh, 2005), education (Vecchiarelli et al., 2005), and medicine (Cullen, 1998). Irrespective of context and/or discipline, however, there are advantages to an actionoriented approach. Schensul (1987) for example, lists several advantages over other forms of applied research. These include:

- $\quad$ Bringing together diverse skill sets and knowledge bases,

- De-mystifying the research process, thus allowing those who will utilize the results the opportunity to understand and shape the data collection process(es),

- Building a research capability in the community/organization that can extend beyond and operate independent of the external researcher,

- Increasing the likelihood that the research results will be used by non-researchers, and

- Improving the quality of the research through access to the community/institution and to key bodies of knowledge.

Mills (1993) makes the theory-generation component of action research more explicit and notes that an action inquiry-based study should attempt to provide:

- Insightful distinctions that tell something new about the phenomena,

- Clear definitions of new concepts at the theoretical, operational, or concrete example levels,

- A cumulative glossary of these ideas within a specific project,

- The interrelations of ideas into patterns or linkages, and

- Findings that are helpful in problem solving within the same broad domain, thus providing some guidance in developing theory. 
Notwithstanding the numerous distinctions and refinements that occur under the rubric of action research, the key definitional and operational aspects of action inquiry can be simplified. This simplification is shown in Figure 1, in a simple 2 x 2 matrix (McTaggart, 1991).

Figure 1. Rubric of Action Research

\begin{tabular}{|l|l|l|}
\hline & Constructive & Reconstructive \\
\hline $\begin{array}{l}\text { Discourse } \\
\text { (Among Participants) }\end{array}$ & $\begin{array}{l}\text { 1.Plan } \\
\text { Prospective to action } \\
\text { (constructed action) }\end{array}$ & $\begin{array}{l}\text { 4. Reflect } \\
\text { Retrospective on observation } \\
\text { (reconnaissance and evaluation) }\end{array}$ \\
\hline $\begin{array}{l}\text { Practice } \\
\text { (In the Social Context) }\end{array}$ & $\begin{array}{l}\text { 2.Act } \\
\text { Retrospective guidance from planning } \\
\text { (deliberate \& controlled strategic action) }\end{array}$ & $\begin{array}{l}\text { 3. Observe } \\
\text { Prospective for reflection } \\
\text { (documentation) }\end{array}$ \\
\hline
\end{tabular}

Source: McTaggart (1991)

Incorporating the commonalities between the various approaches and intentions of action research, this matrix illustrates the cyclical nature of this methodological approach such that:

- Constructive discourse among participants leads to a plan.

- Constructive practice involves acting on that plan.

- $\quad$ Reconstructive practice denotes making observations of the action that has taken place

- Such that reconstructive discourse can occur. This is simply a reflection on these observations such that the plan can be evaluated and modified which brings the process back to stage 1 again.

Therefore, the action research process itself can vary from being largely a predetermined, closed process to an emergent, open process. How one views the role of the researcher - from dominating the action research process to collaboratively managing the process with system members is also an important issue. In the context of this paper, this issue is particularly relevant since senior personnel from the fourteen founding organizations from three distinct organizational sectors, comprised the diverse board of directors of the collaborative venture that served as the focus of the case study; each of whom was keen to contribute to the action research process. In this case study, the role of the researcher was extremely important in attempting to bridge this gap between theory and practice in the simplest form by merely feeding back results to the organization(s) being studied - thus enabling that feedback to inform the decision-making of those involved in managing the collaborative venture.

Next, we consider the case describing the research and the findings in the context of an action orientation and what the implications might be both for the study and practice of multisector collaboration.

\section{THE CASE STUDY REVISITED - THE INSTITUTE OF PHARMACO-ECONOMICS}

In order to gain insights into how best to develop and manage this type of collaboration, the first author conducted an in-depth study using both qualitative and quantitative methods. An action-inquiry orientation guided the design and execution of the study where a rich tradition of previous work in collaborative inter-organizational research provided the conceptual blueprint upon which the inquiry progressed. The research employed an embedded case study design in which the fourteen founding organizations operating within three distinct sectors were represented within one collaborative venture through a board of directors in which the design and conduct of pharmaco/health-economics research to aid in decision making (both organizational and public policy) was the mandate. In working primarily with the founding partners of such a collaborative venture as opposed to the venture itself, a greater understanding of the perspectives of the members of the Board of Directors was desired - those individuals with the dual responsibility of ensuring that the collaborative venture could achieve its objectives while also ensuring that they represented the interests of their respective organizations and sectors throughout the collaborative process.

As such, the research explored the perspectives of the founding Board of Directors of the Institute of Pharmaco-Economics (IPE) seeking to confirm the existence of various factors reported in the literature as 
influencing collaborative venture success as well as to determine whether there were additional success factors within the context of a multi-party, multi-sector collaborative venture. In-depth interviews with each board member involved questions about their respective organizational objectives, motives, indicators of success, challenges as well as what sorts of issues they saw as having the potential to influence outcomes (joint venture survival, performance, partner satisfaction), The intent of the research was to investigate multiple internal perspectives by exploring each sector individually and by obtaining organizational perspectives from each of the partner organizations representing the three different sectors. This was done in order to obtain a truer picture of what constitutes multi-party, multi-sector collaboration. Despite widespread research on the nature of collaboration, and collaborative ventures, in particular, there is a high failure rate associated with them, which warranted this type of investigation.

In this manner, it was possible to see whether the collaborating partners were actually practicing what they preached - insofar as insights from the personal interviews could be compared to what was being expressed in the various draft business/communications plans that were made available. Were the written materials from IPE a genuine reflection of the perspectives of the founding partners? This was particularly important given that the initial steering committee established to investigate the feasibility of creating such a collaborative venture arrived at the conclusion that participation from all three sectors was imperative and would be vital to the success of IPE. To use the terminology of Argyris, conducting this research provided an opportunity to compare instrumental (task-related) and interpersonal (relationship-related) espoused theories of action with theories-in-use, that is, comparing what they claimed was guiding their actions with what was, in fact, guiding their actions (Argyris and Schon, 1974).

Looking at the perspectives of IPE's Board of Directors and analysing these potentially contrasting theories constitute powerful heuristics of reflection and learning (Lipschitz, 2000). A novel and theoretically interesting aspect of IPE is that it provided an opportunity to gain insights into how collaboration can arise and persist, not only with partners representing different sectors, but with the founding partners from the highly competitive industry sector all being multi-national pharmaceutical firms. The study was designed and conducted along an action-inquiry orientation because of the level of involvement that the lead author was expected to play in the ongoing functioning of IPE,. In the context of the in-depth case study of IPE, action oriented inquiry implied a research approach where the process of conducting the research and disseminating the research findings themselves could be used to influence the manner in which IPE operated. This did not constitute 'consulting', since a major objective of action inquiry is the development of novel theory or the refinement of existing theory in addition to taking some kind of action based upon what is being discovered during the research process (Gummesson, 2000); as illustrated by the IPE Board members and their perspectives being used to try and facilitate not only the success of the institute, but also the generation of usable theory on multi-sector collaborative ventures, in general. In addition, a major objective of this research, in addition to learning more about multi-party, multi-sector collaborative ventures, had been to assist in relationship-building among partners through the discovery and incorporation of their perspectives and interests into the ongoing development of this unique collaboration. Because the possibility existed that the first author would assume a stakeholder relations type of role within IPE, the convergence of researcher and Board members into a joint process of meeting both research and collaborative management objectives constitutes what is being coined action-oriented inquiry. As one board member noted:

It puts the doers of research and users of research information in the same camp, so it solves many of these issues related to diffusion, dissemination, and so on.........the results of these studies can get out through the private sector - that's fine. So we win both ways.

This description of the case illustrates the problem that was tackled in this research - what insights could be gained from key informants involved in the establishment of a multi-party, multi-sector collaborative venture in an environment at the time where there was an expressed need for more multi-party, multi-sector collaboration but where, historically, collaborative venture success has not been remarkably high.

This problem area was the motivation for conducting a case study of IPE. Action-oriented research is often participative; implying a partnership between researcher and those involved in the phenomenon of interest. This was the situation with this research, since early discussions with key personnel led to the notion of an action-oriented investigation of the perspectives of IPE's Board members. This form of action research, through the articulation of 
perceived problem areas by Board members and the dissemination of these perspectives to Institute management constituted a social analytic form of action research. Lengthy and detailed interactions between Board members and the researcher led to the identification of a number of problem areas that would need addressing in order for the collaborative venture to realise its objectives. These problem areas were subsequently distilled into a series of normative guidelines that summarised what members of the Institute's board felt would optimise venture success and include:

- $\quad$ There should be an acknowledgement by all partners that there is a "need" to work together cooperatively and that cooperation cannot simply be imposed upon stakeholders through a government mandate (exigency).

- $\quad$ Partners should be aware of issues that have been identified as being (currently or potentially) problematic and then agree on their relative importance (concordance).

- $\quad$ There should be an appreciation that all partners bring something to the collaboration - that each partner has a right to be involved and that they are capable of contributing something of value (legitimacy).

- There should be an awareness and understanding of the environment in which each partner is operating (empathy).

- $\quad$ Partners should support and encourage each other's contribution to the collaboration and there should be mutual promotion of participation (advocacy).

- $\quad$ Partners should share the same overall vision, i.e. improving patient health and well being, and individual organizational goals should be managed and pursued without compromising the overall shared vision (overall shared vision).

- There should be cohesive, coordinated, and consensus perspectives from each represented sector (government, industry and academia) (consensus).

- There should be reassurances that realistic milestones can be achieved, defined expectations can be met, and progress is being made towards achieving the overall shared vision (regular monitoring and review).

These guidelines emerged from an analysis of the case study findings but it is also possible to be more explicit in illustrating how an action-oriented approach led to specific findings. Had this been a typical case study without the action-oriented 'intervention' of the researcher, many of these results might not have been so apparent. It is also probably due to the fact that the action-oriented approach of the research was predicated on the belief that the lead author would assume a stakeholder relations role within the JV upon completion of the research. Rather than being perceived as an 'outside' researcher who would simply gather data and publish the findings, the researcher assumed an 'insider' role and was viewed as using this information to directly influence the operations of the JV. We believe this to be the most important facet of this research i.e., that the interviewed board members were not simply providing information for some academic piece of research, but that their candid responses to some difficult questions were provided with the full knowledge that this was in one sense, an organizational intervention designed to take stock of "where we are and where we want to be" such that research results could inform venture management in real time - thus lessening the gap between theory and action/practice.

Two specific examples of how the action-oriented nature of this research had an influence on the results (results in the sense of changes in practice) are illustrated. In the interviews with board members, an issue that often arose was that 'pharmacoeconomics' was too narrow a descriptor of the institute's mandate. There seemed to be consensus that calling the Institute the 'Institute of Pharmaco-Economics' was too constraining and in fact, conflicted with the larger, longer-term objectives of becoming a world class facility that excelled in the production of 'outcomes' research that could inform all types of health policy; not just pharmaceutical policy. Many of the partners were concerned that the Institute would simply be viewed as a contract research organization in which the pharmaceutical industry partners (as well as other non IPE member pharmaceutical industry firms) would pay to have non-industry researchers conduct pharmacoeconomic studies to determine which drugs were more costeffective than others. Although this type of research did comprise some of IPE's activities, the bigger agenda involved the development of health economics as a science/discipline. Four years after incorporation, the Institute of Pharmaco-Economics did officially change its name to the Institute of Health Economics; reflecting consensus among all partners as to broader mandate of the collaborative venture. This research finding contributed to the 
institute re-branding itself and subsequently being known as the Institute of Health Economics (IHE) as it is now known today.

Table 2: Key Elements of Action-Oriented Research and Corresponding Research Findings

\section{$\underline{\text { Action Research Element }}$}

The improvement of practice

The generation of knowledge about practice

De-mystifying the research process, thus allowing those who will utilize the results the opportunity to understand and shape the data collection process(es),

Uncovering implicit action-related assumptions and beliefs and stakeholder differences

Using the contextually grounded framework of local theory as one interpretive frame for inquiry findings

Bringing together diverse skill sets and knowledge bases

Insightful distinctions that tell something new about the phenomena

\section{Finding}

Joint Venture operational 12 years after creation with additional partners.

Burgeoning literature on the "triple helix' of government-industry-university knowledge creation and utilization.

Venture management intimately involved in shaping the lead author's research proposal and design.

Mutual acknowledgement among partners that research findings could inform Joint Venture management practice as well as 'stock-taking' identifying sectoral differences.

Stakeholders had perceptions as to what factors might influence success of the joint venture.

Participative inquiry representing senior managers with diverse portfolios, representing government, pharma industry and academia

The identification of novel factors believed to influence the success of multisector joint ventures as well as the identification of a novel theoretical perspective (stakeholder theory).

\section{Specific Examples}

Constructive discourse among participants leads to a plan.

Constructive practice involves acting on that plan.

Reconstructive practice denotes making observations of the action that has taken place such that reconstructive discourse can occur.

Reflection on these observations such that the plan can be evaluated and modified.
Candid discussions with IPE Board of Directors leads to plan to re-brand.

Institute of Pharmacoeconomics becomes Institute of Health Economics.

Altered mandate to engage in a broader platform of research.

All health-economics research results made public such that public and organizational policy can be created/amended. 
A second example is illustrated by the fact that a number of board members were not pleased with the apparent level of commitment shown by some of the partner organizations by virtue of appointing lower-level managers to IPE's board. A number of the IPE Board members interviewed made the comment that an important factor that would influence the success of IPE was the actual individuals chosen by their organizations to sit on IPE's board. A key difference was that as opposed to emphasising collaborator profiles as being important, the comments by IPE Board members was that their role and rank within their respective organizations would influence what they brought to the collaborative venture. This led to 'action' whereby all nominated board members to IPE's board had to assume the equivalent of a vice-presidential position/role within their respective parent organization.Table 2 illustrates key action research elements with the corresponding case study findings.

\section{CONCLUSIONS AND FUTURE RESEARCH DIRECTIONS}

Traditional action research seeks to evaluate the results of some sort of organizational intervention. Since this paper reports a study that was established along an action inquiry orientation, the presence of the researcher seeking the perspectives of the participants on issues of importance constitutes an intervention of sorts since it caused the Board of Directors to take stock, and to think about the issues that might influence how the collaborative effort could and would move forward. It was designed as an exercise, not solely to seek insights from the participants that could benefit the researcher in an attempt to make a theoretical, methodological, or empirical contribution to the literature, and by analyzing these insights in the context of existing theory about collaborative ventures, but also as an exercise that could lead to actionable findings that could have an immediate impact on the operations of the focal organization.

As the preliminary results of this research were made available to the Institute and disseminated to senior management and the Board of Directors, there was an opportunity to incorporate the findings into practice; as the two previous examples illustrate. Whether all findings were integrated into various actionable directives within subsequent business plans or internal communications is beyond the scope of this article, but the point to be made is that the research had a practical element that was envisaged as contributing to how best to make this particular collaborative venture succeed. A government sector board member commented:

We need some policies affecting health care that get action as opposed to simply doing research and letting it sit in the literature. One of our missions, [would be] that the research we did in the Institute did not get lost in the literature, but that it was translated into policy.

Whereas most research within the field of inter-organizational relationships focuses primarily on issues of formation and governance, much less attention is being devoted to the actual management of these relationships. The action inquiry orientation of this research demonstrates that the researcher as potential insider could enable frank discussions of issues that needed be considered and addressed by those in a position to manage and guide the venture. A clear understanding and articulation of the dynamics that could facilitate desired outcomes amongst Board members and between Board members and venture management should be critical in directing future research and practice.

Action-oriented research is starting to make an impression in the literature because of its dual objective of theory development/ theory refinement and contribution to practice, where the action orientation endeavors to decrease the gap between theory and practice. The rigor versus relevance debate will continue among academics, but the methodological contribution that this type of research makes is the demonstration that by using an action inquiry methodological approach, it was possible to conduct research - the process of which, actually informed senior management of IPE as well as individual partner representatives on the Board of Directors, about issues relating to the ongoing management of the venture, at the same time introducing the notion of stakeholdership and a stakeholder perspective in collaborative venture development and management - thus meeting the dual objective of theory development/refinement and informing practice such that the gap between theory and practice could be lessened. The results of this case study can be added to those contributing to the growing rationale for utilizing action inquiry oriented methodologies since this approach is most suited to addressing processes rather than variance theories of organizations, since insights from the practitioners come from their experiences in working within and among organizations rather than from their experiences of largely quantitative, variance-based methodologies 
(Hartley and Benington, 2000). In addition, the paper has argued that this methodological approach is very effective in a case study where the focus is on processes in context even though there is a desire to generate ipsative or context-specific theory for the interviewed Board members as well as nomothetic or general theory for the authors and academic researchers in general (Eisenhardt, 1989). The emergence of elements of stakeholder theory and the suggestion of using a stakeholder perspective serves both purposes since stakeholder theory was offered as a possible nomothetic theory for the study of multi-party, multi-sector collaborative ventures as well as ipsative theory for those key individuals involved in the ongoing management of IPE. An opportunity for future research would be to supplement Board of Director perspectives with those of the key individuals actually working within the collaborative venture itself. Not representing any particular founding organization or sector, these perspectives would serve to introduce the venture's perspective on how best to develop and manage such multi-organizational, multi-sector collaborative efforts.

In conducting this research using an action oriented approach, the researcher intervention is a vehicle for enabling the collaborative venture founding partners to take stock of the situation and to better understand the perspectives of their partners. The objective of this article is not to make the point that action research is better at providing insights into particular phenomena of interest as compared to other methodological approaches, but that through the case illustration, action research had the added benefit of immediately feeding research results back into the organization under study such that there was the possibility of these results influencing managerial action in real time. The highly successful multi-sector research collaboration described in this paper continues to create and disseminate new knowledge, transfer this knowledge back into the parent organizations, and it serves as an exemplar to those organizations contemplating strategic responses to the increasingly competitive pressures of globalization and their respective turbulent organizational environments.

Much can be learned from this example of successful collaboration - the Institute is now in its thirteenth year of operations and continues to add partners to the collaborative mix. This would seem to indicate that value has been created for all involved and that the creation of this value is not necessarily based on a cost/benefit analysis neither for those involved, nor for those wishing to gain insights from such collaborative efforts. Theoretical pluralism has its place in the study of phenomena as complex as that which formed the focus of this case study. If insights can be gained through such an analysis that have implications for both theory and practice, then the effort is worthwhile. The paper concludes with another comment from one of the industry board members:

There seemed to be harmony in the sense that we all had somewhat of a common vision, somewhat of a common goal, [we were] somewhat on the same wavelength, and the odds were better than they might otherwise be that it would succeed, because everybody had the same point of view, was heading in the same direction, more or less.... so that it was a collective goal that was moving forward rather than somebody's personal agenda all the time.

\section{AUTHOR INFORMATION}

Michel Rod is a Senior Lecturer in the School of Marketing \& International Business at Victoria University of Wellington in New Zealand. His research interests include service recovery performance, the management of multisector collaboration and pharmaceutical promotion. He has published in the Journal of Strategic Marketing, Journal of Retailing and Consumer Services, Marketing Intelligence and Planning, Managing Service Quality, International Journal of Management, Science and Public Policy, Qualitative Market Research: An International Journal, International Journal of Entrepreneurship and Innovation, journal of Information and Knowledge Management, and International Journal of Pharmaceutical and Healthcare Marketing.

Sarena Saunders is a former Lecturer of Marketing in the School of Marketing and International Business at Victoria University of Wellington. She is currently the Marketing and Communications Group Manager with the New Zealand Retailers Association. Sarena's interests include pharmaceutical marketing, agribusiness marketing and brand management. She has published in The Scientific Journal for Economics and Informatics in Agriculture and the Journal of International Food and Agribusiness Marketing. 


\section{REFERENCES}

1. Argyris, C., and Schon, D. A. (1974), Theory in Practice: Increasing Professional Effectiveness, Jossey-Bass, San Francisco, CA.

2. Cassell, C. and Johnson, P. (2006), “Action Research: Explaining the Diversity”, Human Relations, Vol 59 No 6, pp. 783-814.

3. Chein, I., Cook, S., and Harding, J. (1948), “The Field of Action Research”, American Psychologist, Vol 3, pp. 43-50.

4. Cullen, J. (1998), "The Needle and the Damage Done: Research, Action Research, and the Organizational and Social Construction of Health in the "Information Society", Human Relations, Vol 51 No 12, pp. 1543-1564.

5. Daniel, E., and Wilson, H. (2004), “Action Research in Turbulent Environments”, European Journal of Marketing, Vol 38 No 3/4, pp. 355-377.

6. Elden, M. and Chisholm, R. (1993), "Emerging Varieties of Action Research: Introduction to the Special Issue", Human Relations, Vol 46 No 2, pp. 121-142.

7. Greene, J. (1993), "The Role of Theory in Qualitative Program Evaluation”, in Flinders, D. J. and Mills, G. E. (Eds.), Theory and Concepts in Qualitative Research: Perspectives from the Field, Teachers College Press, Columbia University.

8. Gummesson, E. (2000), Qualitative Methods in Management Research, Sage, Thousand Oaks.

9. Hartley, J. and Benington, J. (2000), "Co-research: A New Methodology for New Times", European Journal of Work and Organizational Psychology, Vol 9 No 4, pp. 463-476.

10. Israel, B., Schurman, S., and Hugentobler, M. (1992), "Conducting Action Research: Relationships Between Organization Members and Researchers", Journal of Applied Behavioral Science, Vol 28 No 1, pp. 74-101.

11. Lewin, K. (1946), “Action research and Minority Problems”, Journal of Social Issues, Vol 2 No 4, pp. 34-46.

12. Lipshitz, R. (2000) Chic, Mystique, and Misconception - Argyris and Schön and the Rhetoric of Organisational Learning, The Journal of Applied Behavioral Science, 36, 4, 456-473.

13. Mårtensson, P., and Lee, A. (2004), "Dialogical Action Research at Omega Corporation", MIS Quarterly, Vol 28 No 3, pp. 507-536.

14. McTaggart, R. (1991), Origins of Educational Action Research, in Action Research: A Short Modern History, Deakin University Press, Geelong, Australia.

15. Mills, G. (1993), "Levels of Abstraction in a Case Study of Educational Change", in Flinders, D. J. and Mills, G. E. (Eds.), Theory and Concepts in Qualitative Research; Perspectives from the Field, Teachers College Press, Columbia University, NY.

16. Nas, P., Prins, W., and Shadid, W. (1987), “A Plea for Praxeology”, in Wenger, G. C. (Ed.), The Research Relationship, Allen \& Unwin, London UK.

17. Perry, C., and Gummesson, E. (2004), “Action Research in Marketing”, European Journal of Marketing, Vol 38 No 3/4, pp. 310-320.

18. Prybutok, V., and Ramasesh, R. (2005), “An Action-Research Based Instrument for Monitoring Continuous Quality Improvement”, European Journal of Operational Research, Vol 166 No 2, pp. 293-309.

19. Reason, P. (2006), "Choice and Quality in Action Research Practice”, Journal of Management Inquiry, Vol 15 No 2, pp. 187-203.

20. Robinson, V. (1993), "Current Controversies in Action Research”, Public Administration Quarterly, Vol 17 No 3, pp. 263-290.

21. Schensul, J., and Stull, D. (1987), "Introduction”, in Stull, D. D. and Schensul, J. J. (Eds.), Collaborative Research and Social Change, Westview Press, Boulder, CO.

22. Schensul, S. (1987), "Perspectives on Collaborative Research", in Stull, D. D. and Schensul, J. J. (Eds.), Collaborative Research and Social Change, Westview Press, Boulder, CO.

23. Susman, G., and Evered, R. (1978), “An Assessment of the Scientific Merits of Action Research”, Administrative Science Quarterly, Vol 23, pp. 582-603.

24. Vecchiarelli, S., Prelip, M., Slusser, W., Weightman, H., and Neumann, C. (2005), "Using Participatory Action Research to Develop a School-Based Environmmental Intervention to Support Healthy Eating and Physical Activity", American Journal of Health Education, Vol 36 No 1, pp. 35-42. 